\title{
Modeling Pressure-Viscosity Behavior of Oil-Based Drilling Fluids
}

\author{
Juan Hermoso, Francisco J. Martínez-Boza* and Críspulo Gallegos \\ Facultad de Ciencias Experimentales, Departamento de Ingeniería Química, Centro de Investigación de Tecnología de Productos y Procesos \\ Químicos (Pro²TecS), Universidad de Huelva, Campus del Carmen, 21071 Huelva - Spain \\ e-mail: martinez@uhu.es \\ * Corresponding author
}

\begin{abstract}
Organoclay suspensions are commonly used as drilling fluids in environments where they are submitted to high pressure and temperature for long periods of time. Consequently, both volumetric and thermorheological properties are among their most important quality parameters concerning this application. The overall objective of this work was to study the pressure and temperature dependence of both viscosity and density for oil-based drilling fluids. With this aim, Pressure-Density-Temperature $(P \rho T)$ data and pressure-viscosity-temperature data were modeled by using different equations. All these equations predict the evolution of the viscosity of drilling fluids with pressure and temperature, for engineering purposes, fairly well.
\end{abstract}

\begin{abstract}
Résumé - Modélisation du comportement pression-viscosité des fluides de forage à base d'huile - Les suspensions d'organo-argiles sont couramment utilisées comme fluides de forage dans des environnements où elles sont soumises à des pressions et des températures élevées pendant de longues périodes. Par conséquent, les propriétés volumétriques et thermo-rhéologiques sont parmi les paramètres de qualité les plus importants pour ce type d'application. L'objectif général de ce travail était d'étudier la dépendance de la viscosité et de la densité en fonction de la pression et de la température des boues de forage à base d'huile. Dans ce but, les données de pression-densitétempérature $(\mathrm{P} \rho \mathrm{T})$ et de pression-viscosité-température ont été modélisées en utilisant différentes équations. Toutes ces équations prédisent assez bien l'évolution de la viscosité des fluides de forage en fonction de la pression et de la température, à des fins d'ingénierie.
\end{abstract}

\section{INTRODUCTION}

Organoclay suspensions are commonly used as oil-based drilling fluids due to their capacity to form gels and their suitable viscous properties. These fluids are submitted to high pressure and temperature in the well during drilling operations. The successful completion of an oil well and its cost depend, on a considerable extent, on the properties of these fluids $[1,2]$. Hence, one of the most interesting points for the drilling industry is to develop fluid formulations, using new nanoscale additives [3, 4], in order to improve their thermophysical properties. Both, viscosity and density have been the two most extensively studied properties of organoclay dispersions used as drilling fluids. When drilling fluids are pumped down, they experience compression and expansion effects related to the increase or decrease of temperature and pressure along the wellbore. Density variations might be significant and its control is a challenging goal to minimize associated risks, and improve security and efficiency, particularly for oily systems [5-7]. Several authors have investigated the combined influence of pressure and temperature on the density of drilling fluids [8-11] However, few papers have been focused on the characterization of the Pressure-Volume-Temperature (PVT) relationship for this type of dispersions $[12,13]$. 
In addition, the rheological behavior of oil drilling fluids is a critical issue in the success of drilling operations. Data concerning the influence of high pressure and temperature on the viscous properties of these types of suspensions are relatively scarce $[14,15]$. However, knowledge of the flow behavior of clay-based drilling fluids, as a function of temperature and pressure, is of a paramount importance in order to solve different important issues, such as excessive torque, gelation, hole cleaning, etc. [16].

Modeling the thermopiezoviscous behavior of fluids is a relevant issue for engineering applications involving processes at high pressure and temperature [17, 18]. In this sense, different equations based on the friction theory [19], the freevolume concept [20,21], and empirical correlations [22] have been proposed to model the combined effect of temperature and pressure on the rheological properties of materials.

The overall objective of this work was to study the influence of pressure and temperature on viscosity and density of model oil-based drilling fluids. With this aim, PressureDensity-Temperature $(\mathrm{P} \rho \mathrm{T})$ data were used to model the volumetric properties of the drilling fluids, by using Equation of State (EoS). Finally, using rheological, PVT, and calorimetric data, the pressure-temperature-viscosity behavior of these suspensions was modeled using different equations, such as Fillers-Moonan-Tschoegl's (FMT), Yasutomi's, and WLF-Barus' models.

\section{EXPERIMENTAL}

\subsection{Materials}

Two commercially available organoclays, denoted as B34 and B128 and provided by Elementis (Belgium), were used in the present study.

A mineral based lubricating oil, SR $10\left(0.916 \mathrm{~g} \mathrm{~cm}^{-3}\right.$ at $40{ }^{\circ} \mathrm{C}$ ) supplied by Verkol (Spain), was used as base oil for the formulation of the model oil-based drilling fluids.

\subsection{Preparation of Organoclay Dispersions}

Oil drilling fluids were prepared by mixing the organoclay (5\% wt.) in SR10 oil base, using a high mixer Ultraturrax (Ika, Germany), at room temperature, at $9000 \mathrm{rpm}$ for $5 \mathrm{~min}$. Prior to its high shear processing, the organoclay was wetted with the oil for $1 \mathrm{~h}$ at room temperature.

\subsection{Density Measurements}

Two vibrating tube densimeters were used to measure the density, $\rho$, of the samples studied. At atmospheric pressure, an Anton Paar DMA 5000 (Austria) was employed to measure the density of SR10 oil and organoclay dispersions between $40{ }^{\circ} \mathrm{C}$ and $100{ }^{\circ} \mathrm{C}$. Prior to performing density measurements with oil and organoclay dispersions at atmospheric pressure, the DMA 5000 densimeter was calibrated, as function of temperature, using both dry air and degasified bi-distilled water as recommended by the manufacturer. The results obtained were compared with the values reported in Anton Paar's manual for air and water in the temperature range used. For this densimeter, the manufacturer cited an uncertainty for temperature of $\pm 0.01{ }^{\circ} \mathrm{C}$, and density of $\pm 5 \times 10^{-6} \mathrm{~g} \mathrm{~cm}^{-3}$, between $0{ }^{\circ} \mathrm{C}$ and $100{ }^{\circ} \mathrm{C}$.

An Anton Paar DMA HPM high-pressure vibrating tube (Austria) was used to measure the density in the temperature range comprised between $40{ }^{\circ} \mathrm{C}$ and $140{ }^{\circ} \mathrm{C}$, and pressures up to 1200 bar. The temperature of the high-pressure vibrating tube was controlled by an external circulating bath using silicone. The temperature was maintained constant within $\pm 0.01{ }^{\circ} \mathrm{C}$. A manual piston intensifier ( $\mathrm{HiP}$, USA) was used to control the pressure of the system. The pressure applied was measured by a pressure transducer model HP-2-S (Wika, Germany) with an uncertainty of less than $0.5 \%$ between 0 and 1600 bar.

The calibration of the HPM vibrating cell, in the entire range of pressure and temperature analyzed, was performed by using a polynomial expression as a function of temperature, pressure, and oscillation period given by Anton Paar:

$$
\begin{aligned}
\rho= & F A_{1}+F A_{2} T+F A_{3} T^{2}+F A_{4} P+F A_{5} P^{2} \\
& +F A_{6} T P+\left(F A_{7}+F A_{8} T+F A_{9} T^{2}\right. \\
& \left.+F A_{10} P+F A_{11} P^{2}+F A_{12} T P\right) \tau^{2}
\end{aligned}
$$

where, $\rho$ is the density of the fluid in $\mathrm{g} \mathrm{cm}^{-3}, T$ the measured temperature in ${ }^{\circ} \mathrm{C}, P$ is the pressure applied in bar, $\tau$ is the oscillation period in $\mathrm{ms}$, and $F A_{i}$ the coefficients of the high-pressure densimeter. These coefficients were evaluated by non-linear regression of Equation (1) to standard densities for both dodecane [23] and water [24].

Taking into account the accuracies of temperature, pressure, period of oscillation, water and dodecane densities, and Equation (1) fitting for the reference fluids $(0.07 \%$ for water and $0.1 \%$ for dodecane), the overall experimental uncertainty in oil and model oil-based drilling fluid densities is estimated to be $\pm 1 \times 10^{-3} \mathrm{~g} \mathrm{~cm}^{-3}$. This uncertainty is similar to that previously reported in the literature [25].

\subsection{Rheological Measurements}

Viscous flow measurements were performed using a controlled stress rheometer, MARS II from Thermo Scientific (Germany). Rheological data were obtained using different geometries: a conventional coaxial cylinder geometry (41 mm inner diameter, $1 \mathrm{~mm}$ gap, $60 \mathrm{~mm}$ length) and a serrated plate-and-plate geometry ( $35 \mathrm{~mm}$ diameter, $1 \mathrm{~mm}$ gap) 
for rheological tests at atmospheric pressure; a coaxial cylinder geometry ( $38 \mathrm{~mm}$ diameter, $80 \mathrm{~mm}$ length) and a Double Helical Ribbon (DHR) geometry (36 mm diameter, $78 \mathrm{~mm}$ length), coupled with a pressure cell (D400/200), for measurements at high pressure. DHR is a non-conventional geometry, calibrated with a Newtonian fluid and several shear-thinning fluids, in the pressure range used in the present study [26]. The cell D400/200 is a pressure vessel of $39 \mathrm{~mm}$ inner diameter. Inside the cell, the coaxial cylinder and the DHR geometry were put in contact with a sapphire surface, at the bottom of the vessel, by a steel needle. The inner geometry was equipped, at the top, with a secondary magnetic cylinder (36 $\mathrm{mm}$ diameter, $8 \mathrm{~mm}$ length), magnetically coupled to a tool outside the cell, which was connected to the motor-transducer of the rheometer. The pressure cell was connected to a hydraulic pressurization system, which consists of two units, a high pressure valve and a hand pump (Enerpac, USA), connected by a high pressure line. The pressure cell was pressurized using, as pressurizing liquid, the same fluid to be tested. A pressure transducer GMH 3110 (Gresingeg Electronic, Germany), able to measure differential pressures ranging from 0 to $400 \mathrm{bar}$ ( 0.1 bar resolution), was used.

Steady-state viscosity measurements, at different differential pressures $(0,100,200,300$ and 390 bar $)$ and temperatures $\left(40,80,100,120\right.$ and $\left.140{ }^{\circ} \mathrm{C}\right)$, were performed in a shear rate range dependent on sample viscosity. The temperature in the high pressure cell was regulated with circulating silicone bath (DC30 Thermo Scientific, Germany), with an uncertainty of $\pm 0.1{ }^{\circ} \mathrm{C}$.

\subsection{Differential Scanning Calorimetry}

Differential Scanning Calorimetry (DSC) tests were carried out with a DSC-Q100 calorimeter (TA Instruments, USA), using 5-10 mg samples sealed in hermetic aluminium pans. The sample was purged with dry nitrogen at a flow rate of $50 \mathrm{~mL} / \mathrm{min}$, to avoid any condensation of moisture. First, the pans where placed onto the cell at room temperature, then were heated at $80^{\circ} \mathrm{C}$, kept at this temperature for $5 \mathrm{~min}$ to reach the thermodynamic equilibrium, and subsequently, the samples were quenched-cooled to $-80^{\circ} \mathrm{C}$, at $10{ }^{\circ} \mathrm{C} / \mathrm{min}$, kept for $5 \mathrm{~min}$ at this temperature to reach the equilibrium, and, finally, heated, at $10{ }^{\circ} \mathrm{C} / \mathrm{min}$, up to $180{ }^{\circ} \mathrm{C}$. The glass transition temperature was determined from the inflection point of the step-like decrease in the heat flow.

\section{RESULTS AND DISCUSSION}

\subsection{Viscous Flow Behavior}

Figures $1 \mathrm{a}$ and $1 \mathrm{~b}$ show the steady-state viscous flow curves of the samples studied (SR10 oil, and B34- and B128-based

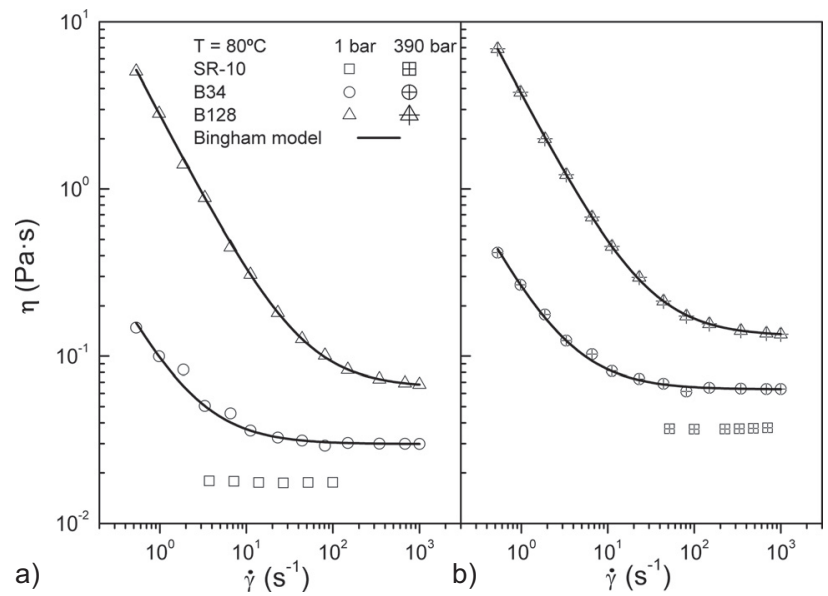

Figure 1

Experimental steady-state viscous flow curves, and Bingham's model fitting, for SR10 oil, B34- and B128-based drilling fluids $\left(T=80^{\circ} \mathrm{C}\right.$; a) $P=1$ bar; b) $P=390$ bar).

oily fluids), at $80{ }^{\circ} \mathrm{C}$ and pressures of 1 and 390 bar respectively. In the case of the oily suspensions, the steady-state viscous flow curves were obtained after upward and downward shear stress sweep tests, as has been described by the authors elsewhere [27, 28].

As can be observed in Figure 1, the viscous behavior of the SR10 oil is Newtonian in the pressure range of 1-390 bar, at $80{ }^{\circ} \mathrm{C}$. This oil also behaves as a Newtonian liquid for the whole range of temperature tested $\left(40-140{ }^{\circ} \mathrm{C}\right)$. In contrast, oil drilling fluids show a shear-thinning behavior, exhibiting a Bingham-law dependence of viscosity with shear rate in the whole range of pressure and temperature tested $\left(1-390\right.$ bar; $\left.40-140{ }^{\circ} \mathrm{C}\right)$, as has been previously reported $[27,28]$.

The Newtonian viscosity of the SR 10 oil sample increases up to 2.13 times from atmospheric pressure to 390 bar, at $80{ }^{\circ} \mathrm{C}$. However, the viscosity-pressure relationship for the drilling fluids is more complex, depending on both bentonite nature and shear rate. For example, the plastic viscosity increases $\sim 2.11$ times for B34 sample and $\sim 2.22$ times for B128 sample, in the above-mentioned range of pressure. Nevertheless, at a shear rate of $1 \mathrm{~s}^{-1}$, the plastic viscosity increases $\sim 2.68$ times for B34 sample and $\sim 1.34$ times for B128 sample. This complex piezoviscous behavior has been related to the development of complex molecular structures with different sensitivities to pressure and shear rate [29].

The thermopiezoviscous behavior of these materials can be modeled using equations developed for thermopiezorheologically simple materials, such as the FMT [30] the Yasutomi [31] or the empirical WLF-Barus factorial model [27]. The approach is based on selecting characteristic 
rheological parameters, such as the Newtonian viscosity, in the case of the SR10 oil, or the plastic viscosity $\left(\eta_{\mathrm{p}}\right)$ of the model drilling fluids, to eliminate the complex shear-rate dependence of the piezoviscous behavior, fitting the model equations to these selected shear-rate independent parameters.

Viscosity-pressure-temperature models can be also classified as either only based on empirical parameters or based on some physical properties. Thus, the FMT model takes into account the pressure dependence of the bulk modulus and the expansivity. The pressure dependence of these properties can be obtained from the evolution of the density with pressure and temperature using the Murnaghan EoS. The Yasutomi model is described as a function of the glass transition temperature, which can be obtained from DSC measurements. The WLF-Barus model describes the thermopiezoviscous behavior using empirical parameters for both temperature and pressure. To apply either FMT's or Yasutomi's model based on physical properties, the bulk modulus or the glass transition temperature should be previously determined by additional experiments.

\subsection{Density-Pressure-Temperature Behavior}

Figures 2-4 show the values of the density for the different samples studied, as a function of pressure (1-1200 bar) and temperature $\left(40{ }^{\circ} \mathrm{C}\right.$ up to $\left.140{ }^{\circ} \mathrm{C}\right)$. As expected, a nearly linear decrease in density with temperature is observed for all samples in the range of temperature studied. Temperature and pressure exert an opposite influence on the volumetric behavior. The decrease in density when temperature is raised from $40{ }^{\circ} \mathrm{C}$ to $140{ }^{\circ} \mathrm{C}$ is compensated by an increase in pressure from 1 to $\sim 1056$ bar, for the SR10 oil and even slightly higher for both oil-based drilling fluids (up to $\sim 1105$ and $\sim 1060$ for B34 and B128, respectively). Thus, the influence of temperature is more relevant as compared to that of pressure. On the basis of this analysis, both model drilling fluids, B34 and B128, are slightly more susceptible to temperature than the base oil, showing the B34-based drilling fluid the lowest susceptibility to pressure, at $140{ }^{\circ} \mathrm{C}$. These drilling fluids show quite similar temperature susceptibility to that of the synthetic oil-based drilling fluids studied at low pressure [6]. On the contrary, these fluids show higher temperature susceptibility than those studied at high pressure [9].

The experimental evolution of the density, $\rho$, with both temperature and pressure can be described by the Murnaghan equation [32]:

$$
\frac{\rho}{\rho_{0}(0, T)}=\left(\frac{K_{\mathrm{e}}(T)+k_{\mathrm{e}} P}{K_{\mathrm{e}}(T)+k_{\mathrm{e}} P_{\text {ref }}}\right)^{1 / k_{\mathrm{e}}}
$$

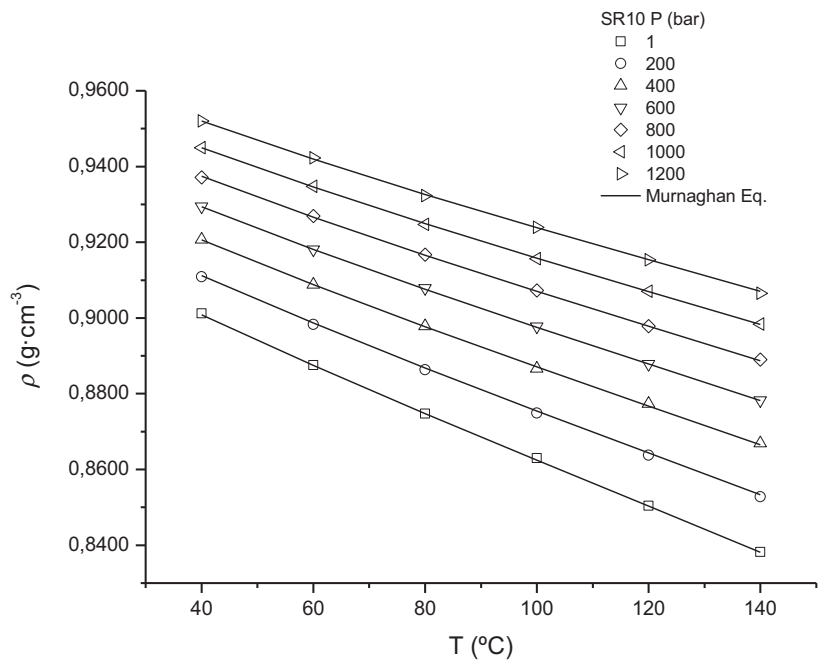

Figure 2

Experimental density values, and Murnaghan's equation fitting, for SR10 oil, as a function of pressure and temperature.

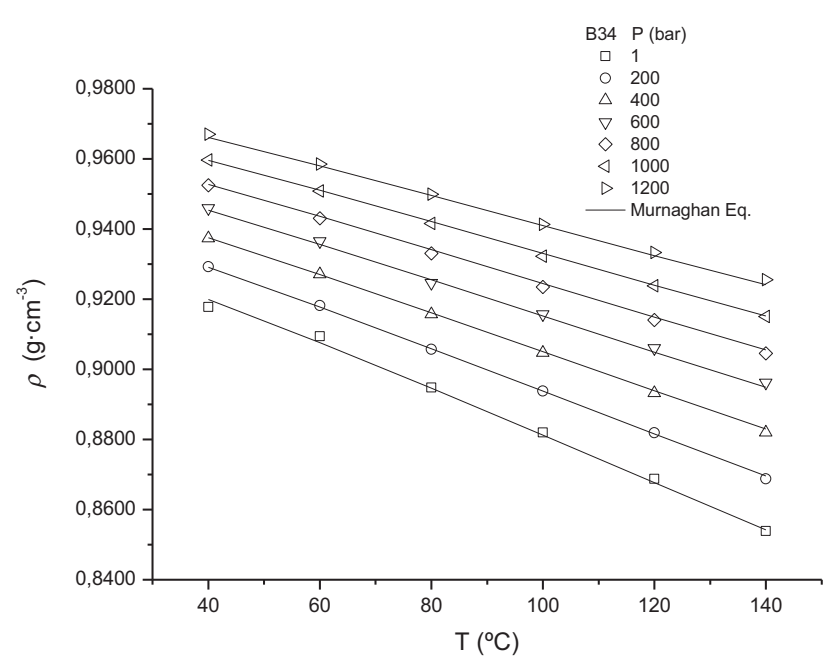

Figure 3

Experimental density values, and Murnaghan's equation fitting, for B34-based drilling fluid, as a function of pressure and temperature.

being

$$
\begin{gathered}
\rho_{0}(0, T)=a_{0}+a_{1}\left(T-T_{\text {ref }}\right)+a_{2}\left(T-T_{\text {ref }}\right)^{2} \\
+a_{3}\left(T-T_{\text {ref }}\right)^{3} \\
K_{\mathrm{e}}(T)=K_{\mathrm{e}}^{*} \exp \left(-\lambda\left(T-T_{\text {ref }}\right)\right)
\end{gathered}
$$

The polynomial function, $\rho_{0}(0, T)$, represents the evolution of the density, at the reference pressure, where $T_{\text {ref }}$ is the reference temperature $\left(80{ }^{\circ} \mathrm{C}\right)$ and $a_{0}, a_{1}, a_{2}$, and $a_{3}$ 


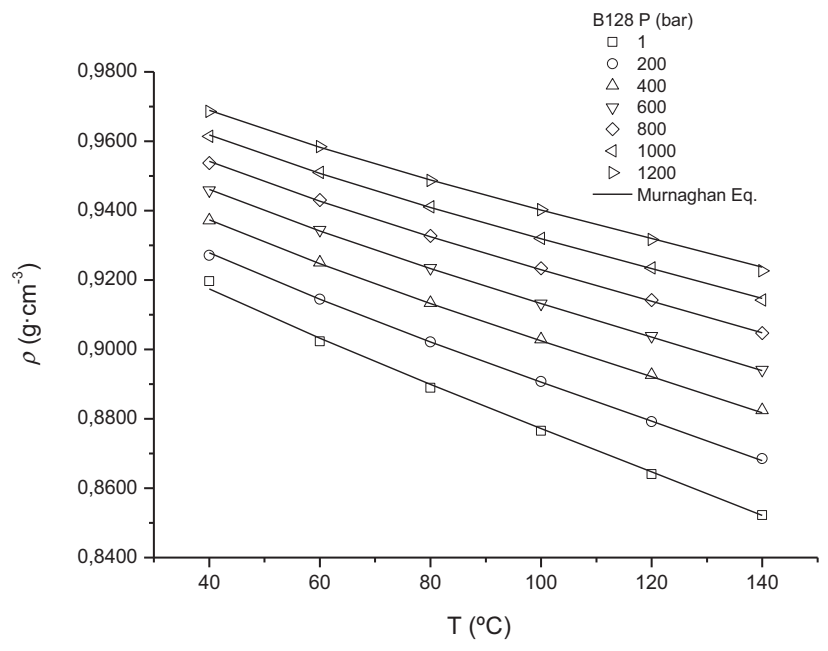

Figure 4

Experimental density values, and Murnaghan's equation fitting, for B128-based drilling fluid, as a function of pressure and temperature.

are fitting parameters, whose values, for the samples studied, are presented in Table 1. $K_{\mathrm{e}}(T)$ represents the temperature dependence of the bulk modulus of the entire volume, being $K_{\mathrm{e}}^{*}$ the bulk modulus at zero pressure and temperature of reference; $k_{\mathrm{e}}$ is an empirical constant, the Bridgman constant, that implies a linear dependence of the bulk modulus with pressure [21]; and $\lambda$ defines the temperature dependence of the bulk modulus at any given pressure [33] ( $\lambda=m \alpha_{\mathrm{e}}^{*}$, being $m$ an empirical constant and $\alpha_{\mathrm{e}}^{*}$ the thermal expansivity of the entire volume at zero pressure and temperature of reference). The values of $K_{\mathrm{e}}^{*}, k_{\mathrm{e}}$ and $\lambda$ are also presented in Table 1 .

As can be seen in Figures 2-4, the Murnaghan equation describes the density evolution in the range of temperature and pressure studied fairly well. This equation has been extensively used by other authors to fit data of volumetric properties, as a function of temperature and pressure, of rubbery polymers [33] and heavy petroleum fractions [34]. For these samples, the values of the Percent Average Absolute Relative Deviation (\%AARD), shown in Table 1, are lower than 0.07 , indicating that this model is suitable for oil-based drilling fluids.

The evolution of the bulk modulus of the entire volume, $K_{\mathrm{e}}$, with pressure, at the reference temperature $\left(80^{\circ} \mathrm{C}\right)$, is shown in Figure 5. The Murnaghan equation predicts a linear increase of the bulk modulus with pressure, as follows:

$$
K_{\mathrm{e}}(P)=K_{\mathrm{e}}^{*}+k_{\mathrm{e}} P
$$

In the range of pressure tested, both oil and drilling fluids show a qualitatively similar linear increase in the bulk modulus with pressure. This fact suggests that the volumepressure behavior for these fluids is determined by that of
TABLE 1

Murnaghan's equation fitting parameters of PVT data modeling for the samples studied.

\begin{tabular}{c|c|c|c}
\hline Parameters & $\mathrm{SR} 10$ & $\mathrm{~B} 34$ & $\mathrm{~B} 128$ \\
\hline$a_{0}\left(\mathrm{~g} \mathrm{~cm}^{-3}\right)$ & 0.8747 & 0.8946 & 0.8898 \\
\hline$a_{1}\left(\mathrm{~g} \mathrm{~cm}^{-3}{ }^{\circ} \mathrm{C}^{-1}\right)$ & $-6.24 \times 10^{-4}$ & $-6.6 \times 10^{-4}$ & $-6.46 \times 10^{-4}$ \\
\hline$a_{2}\left(\mathrm{~g} \mathrm{~cm}^{-3}{ }^{\circ} \mathrm{C}^{-2}\right)$ & $4.9 \times 10^{-6}$ & $-5 \times 10^{-7}$ & $7 \times 10^{-7}$ \\
\hline$a_{3}\left(\mathrm{~g} \mathrm{~cm}^{-3}{ }^{\circ} \mathrm{C}^{-3}\right)$ & $-4 \times 10^{-9}$ & $4 \times 10^{-9}$ & $-7 \times 10^{-9}$ \\
\hline$k_{\mathrm{e}}$ & 9.50 & 9.51 & 9.49 \\
\hline$K_{\mathrm{e}}^{*}(\mathrm{bar})$ & $1.358 \times 10^{4}$ & $1.49 \times 10^{4}$ & $1.357 \times 10^{4}$ \\
\hline$\lambda\left({ }^{\circ} \mathrm{C}^{-1}\right)$ & $4.8 \times 10^{-3}$ & $6.3 \times 10^{-3}$ & $5.3 \times 10^{-3}$ \\
\hline$m$ & 6.734 & 8.536 & 7.290 \\
\hline$\alpha_{\mathrm{e}}^{*}\left({ }^{\circ} \mathrm{C}^{-1}\right)$ & $7.14 \times 10^{-4}$ & $7.38 \times 10^{-4}$ & $7.27 \times 10^{-4}$ \\
\hline Statistic & 0.026 & 0.070 & 0.041 \\
\hline $\begin{array}{c}\text { Residual sum } \\
\text { of squares }\end{array}$ & $4.8 \times 10^{-6}$ & $3.2 \times 10^{-5}$ & $1.4 \times 10^{-5}$ \\
\hline$R^{2}$ & 0.999 & 0.999 & 0.999 \\
\hline $\begin{array}{c}\text { Standard } \\
\text { deviation }\end{array}$ & $3.6 \times 10^{-4}$ & $9.4 \times 10^{-4}$ & $6.3 \times 10^{-4}$ \\
\hline \begin{tabular}{c}
${ }_{0} \mathrm{AARD}$ \\
\hline
\end{tabular} & & & \\
\hline
\end{tabular}

the base oil, as has been pointed out by other authors [10]. The values of the bulk modulus, calculated from PVT data, at $1 \mathrm{bar}$ and $80^{\circ} \mathrm{C}$, are similar and slightly higher than those obtained for $n$-paraffinic based drilling fluids [6] and mineral oil-based mud $[8,9]$ respectively, being the pressure susceptibility slightly higher for the samples studied.

The evolution of the expansivity, $\alpha_{\mathrm{e}}(P)$, at constant temperature $\left(80^{\circ} \mathrm{C}\right)$, for the oil and oil-based drilling fluids studied is shown in Figure 6. A decrease in the expansivity values with pressure is observed for all the samples. According to the Murnaghan EoS, the isothermal expansivity can be described as follows:

$$
\alpha_{\mathrm{e}}(P)=\alpha_{\mathrm{e}}^{*}\left(\frac{m P}{K_{\mathrm{e}}^{*}+k_{\mathrm{e}} P}\right)
$$

Values for both the expansivity of the entire volume, $\alpha_{\mathrm{e}}^{*}$, and the empirical parameter, $m$, are also presented in Table 1 . As can be observed, the model drilling fluids present expansivity values at zero pressure slightly higher than the SR10 oil, more significantly for B34-based drilling fluid, indicating that these suspensions are more compressible than the base oils. This fact suggests an increase in the free volume fraction of the suspension due to interactions between the oil and the organic chains of the organobentonite. 


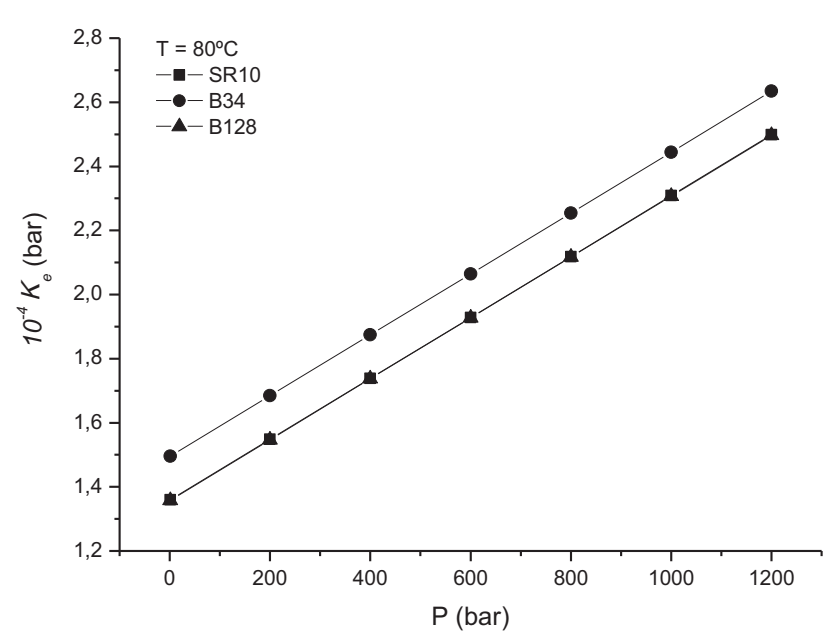

Figure 5

Evolution of the entire bulk modulus for SR10 oil, B34 and B128-based drilling fluids, as function of pressure, at $80{ }^{\circ} \mathrm{C}$.

Nevertheless, this effect vanishes as pressure increases, being the expansivities of the oil drilling fluids similar to that of the base oil at $400 \mathrm{bar}$, and even lower at higher pressures. These model drilling fluids show lower expansivity values than those formulated with mineral and vegetal oils [5].

\subsection{Temperature-Pressure-Viscosity Relationship}

The FMT model has been successfully used for modeling the pressure and temperature dependence of heavy and intermediate fuel and recycled oils viscosities [34-36]. Models based on molecular theories have the advantage of predicting the evolution of the rheological properties on the basis of the temperature-pressure evolution of some physical properties, such as expansivity and compressibility in the case of the FMT model. This model expresses the viscosity-pressure-temperature relationship as a function of molecular parameters:

$$
\ln \left(\frac{\eta}{\eta_{\text {ref }}}\right)=\frac{2.303 c_{1}^{00}\left(T-T_{\text {ref }}-\theta(P)\right)}{c_{2}(P)\left(T-T_{\text {ref }}-\theta(P)\right)}
$$

being

$$
\begin{gathered}
\theta(P)=c_{3}(P) \ln \left(\frac{1+c_{4} P}{1+c_{4} P_{\text {ref }}}\right)-c_{5}(P) \ln \left(\frac{1+c_{6} P}{1+c_{6} P_{\text {ref }}}\right) \\
c_{1}^{00}=B / 2.203 f_{0}
\end{gathered}
$$

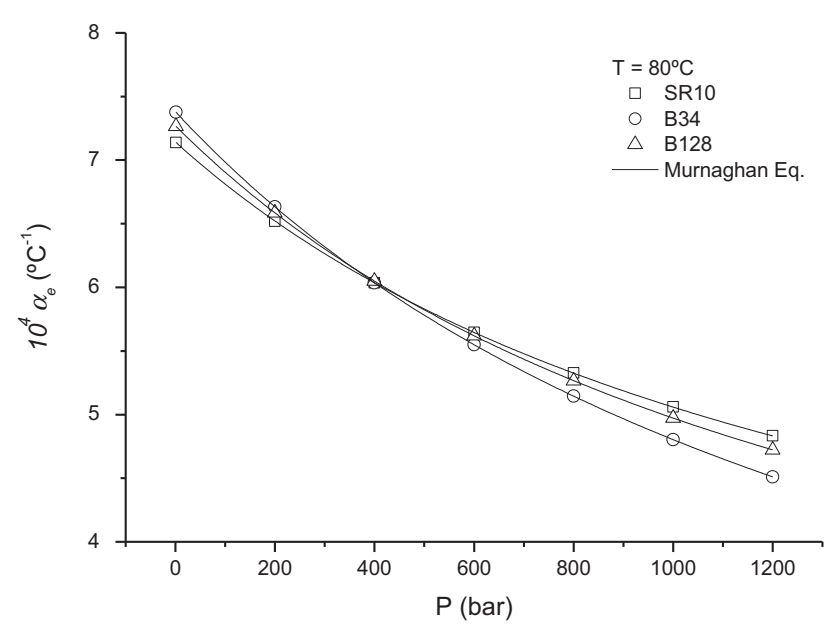

Figure 6

Evolution of the thermal expansivity for SR 10 oil and oil-based drilling fluids, as a function of pressure, at $80{ }^{\circ} \mathrm{C}$.

$$
\begin{gathered}
c_{2}(P)=f_{0} / \alpha_{\mathrm{f}}(P) \\
c_{3}(P)=1 / k_{\mathrm{e}} \alpha_{\mathrm{f}}(P) \\
c_{4}=k_{\mathrm{e}} / K_{\mathrm{e}}^{*} \\
c_{5}(P)=1 k_{\phi} \alpha_{\mathrm{f}}(P) \\
c_{6}=k_{\phi} / K_{\phi}^{*} \\
\alpha_{\mathrm{f}}(P)=\alpha_{\mathrm{e}}(P)-\alpha_{\phi}(P)=\alpha_{\mathrm{f}}^{*}\left(1-\frac{m P}{K_{\mathrm{e}}^{*}+k_{\mathrm{e}} P}\right) \\
-m \alpha_{\phi}^{*} P\left(\frac{1}{K_{\mathrm{e}}^{*}+k_{\mathrm{e}} P}-\frac{1}{K_{\phi}^{*}+k_{\phi} P}\right)
\end{gathered}
$$

where, $\eta_{\text {ref }}$ is the viscosity at the reference temperature and pressure; $f_{0}$ is the fractional free-volume at the reference temperature; $B$ is a constant; $\alpha_{\mathrm{f}}(P)$ is the expansivity of the free-volume, considered pressure dependent and temperature independent; $\alpha_{\mathrm{f}}^{*}$ is the expansivity of the free volume at zero pressure and temperature of reference, $\alpha_{\phi}^{*}$ is the expansivity of the occupied volume at zero pressure and temperature of reference; $K_{\phi}^{*}$ are the bulk moduli of occupied volume, at zero pressure and temperature of reference; $k_{\phi}$ is the Bridgman constant for the occupied volume, the superscript 00 indicates temperature and pressure of reference.

With the coefficients $K_{\mathrm{e}}^{*}, k_{\mathrm{e}}$ and $m$ determined from density measurements, the experimental viscosities can be used to determine the remaining parameters of the model $\left(\eta_{\mathrm{ref}}, B\right.$, $\left.f_{0}, k_{\phi}, K_{\phi}^{*}, \alpha_{\mathrm{f}}^{*}, \alpha_{\phi}^{*}\right)$, by fitting the set of Equations (7)-(15), 
where $\eta_{\text {ref }}$ depends on the temperature and pressure of reference, arbitrarily selected, and $\alpha_{f}^{*}, \alpha_{\phi}^{*}$ are constrained by the PVT behavior since $\alpha_{\mathrm{e}}^{*}=\alpha_{\mathrm{f}}^{*}+\alpha_{\phi}^{*}$. The values obtained for these parameters are shown in Table 2.

Among the models based on the free-volume concept, the Yasutomi model [37] has been extensively applied to model the pressure-temperature-viscosity relationship for polyethylene and different lubricant oils [38]. This model includes material properties at the glassy state:

$$
\log \left(\frac{\eta}{\eta_{\mathrm{g}}}\right)=\frac{c_{1}\left(T-T_{\mathrm{g}}\right) F}{c_{2}+\left(T-T_{\mathrm{g}}\right) F}
$$

where $\eta_{\mathrm{g}}$ is the viscosity at $T_{\mathrm{g}}$, the glass transition temperature, which is a function of pressure:

$$
T_{\mathrm{g}}=T_{\mathrm{g} 0}+A_{1} \ln \left(1+A_{2}\left(P-P_{\text {ref }}\right)\right)
$$

and $F$ is the free volume expansivity,

$$
F=1-B_{1} \ln \left(1+B_{2}\left(P-P_{\text {ref }}\right)\right)
$$

being the expression for an improved definition [31]:

$$
F=1-B_{1}\left(P-P_{\text {ref }}\right)^{B_{2}}
$$

where $T_{\mathrm{g} 0}$ is the gas transition temperature at reference pressure; and $c_{1}, c_{2}, A_{1}, A_{2}, B_{1}$ and $B_{2}$ the parameters to be evaluated.

The range of pressure tested in this research is much narrower than that normally covered for lubricant studies [37]. Consequently, the viscosity-pressure evolution is simpler than that obtained for lubricant oils submitted to higher pressure. In these cases, the Yasutomi equation would be overparameterized, leading to several set of parameters from the regression procedure of the viscosity-pressure data. Consequently, in this fitting process, $\eta_{\mathrm{g}}$ and $B_{2}$ have been arbitrarily set to $10^{12} \mathrm{~Pa} \mathrm{~s}$ and 1 respectively, using the $T_{\mathrm{g} 0}$ values from DSC measurement as additional fixed parameters. The results obtained for the remaining parameters are shown in Table 3.

Finally, the WLF-Barus model combines two well-known exponential equations, the WLF and a generalized version of the Barus equation, to describe both temperature and pressure effects on the viscosity:

$$
\begin{aligned}
\eta=\eta_{\text {ref }} \exp [ & \left(-\frac{2.303 c_{1}\left(T-T_{\text {ref }}\right)}{c_{2}+\left(T-T_{\text {ref }}\right)}\right) \\
& \left.\left(\left(\beta_{0}+\beta_{1}\left(T-T_{\text {ref }}\right)\right)\left(P-P_{\text {ref }}\right)\right)\right]
\end{aligned}
$$

TABLE 2

Values of the different FMT model parameters for the samples studied $\left(T_{\text {ref }}=80^{\circ} \mathrm{C} ; P_{\text {ref }}=1\right.$ bar $)$.

\begin{tabular}{c|c|c|c}
\hline Parameters & SR10 & B34 & B128 \\
\hline$\eta_{\text {ref }}($ Pa s) & 0.016 & 0.028 & 0.059 \\
\hline$B$ & 0.389 & 0.419 & 0.353 \\
\hline$f_{0}$ & 0.091 & 0.097 & 0.096 \\
\hline$k_{\phi}$ & 10.0 & 8.6 & 8.4 \\
\hline$K_{\phi}^{*}($ bar $)$ & $3.1 \times 10^{4}$ & $4.30 \times 10^{4}$ & $4.40 \times 10^{4}$ \\
\hline$\alpha_{\mathrm{f}}^{*}\left({ }^{\circ} \mathrm{C}^{-1}\right)$ & $7.10 \times 10^{-4}$ & $7.30 \times 10^{-4}$ & $7.10 \times 10^{-4}$ \\
\hline$\alpha_{\phi}^{*}\left({ }^{\circ} \mathrm{C}^{-1}\right)$ & $4 \times 10^{-6}$ & $8 \times 10^{-6}$ & $1.6 \times 10^{-5}$ \\
\hline Statistics & 0.022 & 0.103 & 0.041 \\
\hline $\begin{array}{c}\text { Residual sum } \\
\text { of squares }\end{array}$ & 0.998 & 0.985 & 0.993 \\
\hline$R^{2}$ & 0.03 & 0.08 & 0.05 \\
\hline $\begin{array}{c}\text { Standard } \\
\text { deviation }\end{array}$ & 2.30 & 5.41 & 3.93 \\
\hline \begin{tabular}{c} 
\%AARD \\
\hline
\end{tabular} & & & \\
\hline
\end{tabular}

TABLE 3

Values of the different parameters of the modified Yasutomi model for the samples studied $\left(T_{\text {ref }}=80^{\circ} \mathrm{C} ; P_{\text {ref }}=1\right.$ bar $)$.

\begin{tabular}{c|c|c|c}
\hline Parameters & SR10 & B34 & B128 \\
\hline$\eta_{\mathrm{g}}(\mathrm{Pa} \mathrm{s})$ & $1 \times 10^{12}$ & $1 \times 10^{12}$ & $1 \times 10^{12}$ \\
\hline$c_{1}$ & 16.05 & 15.81 & 15.06 \\
\hline$c_{2}\left({ }^{\circ} \mathrm{C}\right)$ & 23.71 & 24.43 & 20.31 \\
\hline$T_{\mathrm{g} 0}\left({ }^{\circ} \mathrm{C}\right)$ & -61.8 & -63.5 & -63.5 \\
\hline$A_{1}$ & 79689 & 110.63 & 197.59 \\
\hline$A_{2}\left(\right.$ bar $\left.^{-1}\right)$ & $5.5 \times 10^{-7}$ & $4.458 \times 10^{-4}$ & $2.891 \times 10^{-4}$ \\
\hline$B_{1}\left(\right.$ bar $\left.^{-1}\right)$ & 1 & 1 & 1 \\
\hline$B_{2}$ & $-3.51 \times 10^{-3}$ & $-1.74 \times 10^{-3}$ & $-2.73 \times 10^{-3}$ \\
\hline Statistic & 4.84 & 4.78 & 0.026 \\
\hline $\begin{array}{c}\text { Residual sum } \\
\text { of squares }\end{array}$ & 0.107 & 0.080 & 0.995 \\
\hline$R^{2}$ & 0.991 & 0.988 & 0.041 \\
\hline $\begin{array}{c}\text { Standard } \\
\text { deviation }\end{array}$ & 0.065 & 0.073 & \\
\hline \begin{tabular}{c} 
\%AARD \\
\hline
\end{tabular} & & & \\
\hline
\end{tabular}


TABLE 4

Values of the different parameters of the WLF-Barus model for the samples studied $\left(T_{\text {ref }}=80^{\circ} \mathrm{C} ; P_{\text {ref }}=1 \mathrm{bar}\right)$.

\begin{tabular}{c|c|c|c}
\hline Parameters & SR10 & B34 & B128 \\
\hline$\eta_{\text {ref }}(\mathrm{Pa} \mathrm{s})$ & 0.016 & 0.029 & 0.060 \\
\hline$c_{1}$ & 1.69 & 1.84 & 1.58 \\
\hline$c_{2}\left({ }^{\circ} \mathrm{C}\right)$ & 120.0 & 137.7 & 138.7 \\
\hline$\beta_{0}\left(\mathrm{bar}^{-1}\right)$ & $2.00 \times 10^{-3}$ & $1.94 \times 10^{-3}$ & $2.04 \times 10^{-3}$ \\
\hline$\beta_{1}\left(\mathrm{bar}^{-1}{ }^{\circ} \mathrm{C}^{-1}\right)$ & $-1.4 \times 10^{-5}$ & $-2.2 \times 10^{-5}$ & $-2.1 \times 10^{-5}$ \\
\hline Statistics $^{-1}$ & 0.022 & 0.073 & 0.034 \\
\hline $\begin{array}{c}\text { Residual sum of } \\
\text { squares }\end{array}$ & 0.998 & 0.989 & 0.994 \\
\hline$R^{2}$ & 0.029 & 0.070 & 0.047 \\
\hline $\begin{array}{c}\text { Standard } \\
\text { deviation }\end{array}$ & 2.36 & 3.98 & 3.43 \\
\hline \%AARD & & &
\end{tabular}

where $c_{1}$ and $c_{2}$ are empirical constants. The piezoviscous coefficient, $\beta_{s}$, has been linearized with temperature in order to generalize the model. The results obtained from the application of the WLF-Barus model to the viscosity data are shown in Table 4.

Figure 7 shows the evolution with pressure of the Newtonian viscosity, for SR10 oil, and the plastic viscosity, for B34- and B128-based oil drilling fluids, at the reference temperature $\left(80^{\circ} \mathrm{C}\right)$ as example. It can be seen that, at constant temperature, viscosity increases exponentially with pressure in the range of pressure tested. In addition, all the three models tested describe the isothermal evolution of viscosity with pressure, for engineering purposes, fairly well.

In Figure 8, the experimental viscosity data (in the range 1-400 bar and $40-140{ }^{\circ} \mathrm{C}$ ) of the samples studied and the calculated ones by using different models are compared (Fig. 8a: FMT's model; Fig. 8b: Yasutomi's model; and Fig. 8c: WLF-Barus' model). As can be seen, the largest deviations between experimental and calculated values are observed for B34 and B128 model drilling fluids, at $140{ }^{\circ} \mathrm{C}$. These deviations, previously explained by the authors [27] are a consequence of the influence, on the rheological behavior of these drilling fluids, of the gelation process induced at high temperature. Excluding the results obtained at the above-mentioned temperature $\left(140{ }^{\circ} \mathrm{C}\right)$, the three models fit the experimental results, in the whole range of temperature and pressure tested, fairly well (average error less than $5 \%$ ). Nevertheless, on the basis of the \%AARD and relative deviation, each model behaves differently

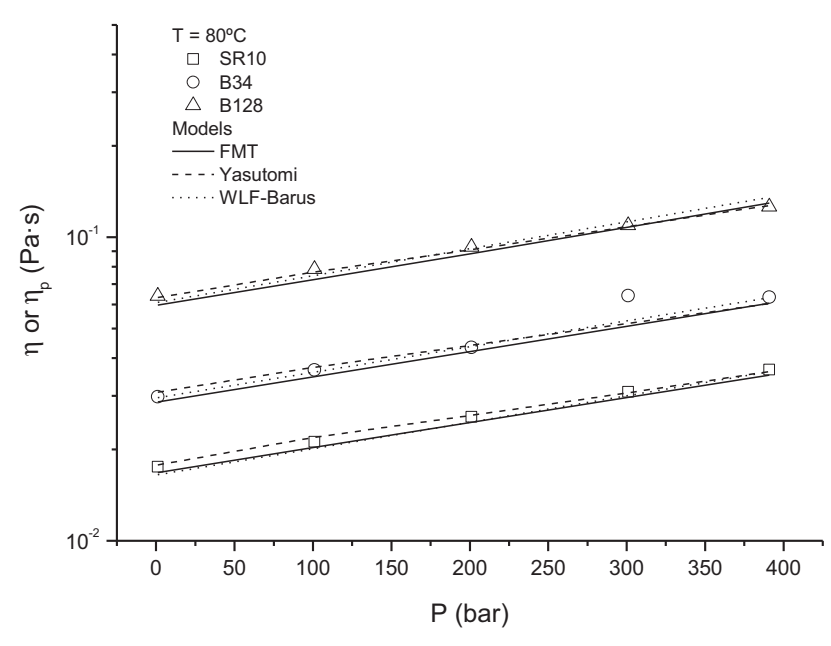

Figure 7

Experimental and estimated viscosities, using FMT, Yasutomi and WLF-Barus models, for SR10 oil and drilling fluids, as a function of pressure, at $80{ }^{\circ} \mathrm{C}$.

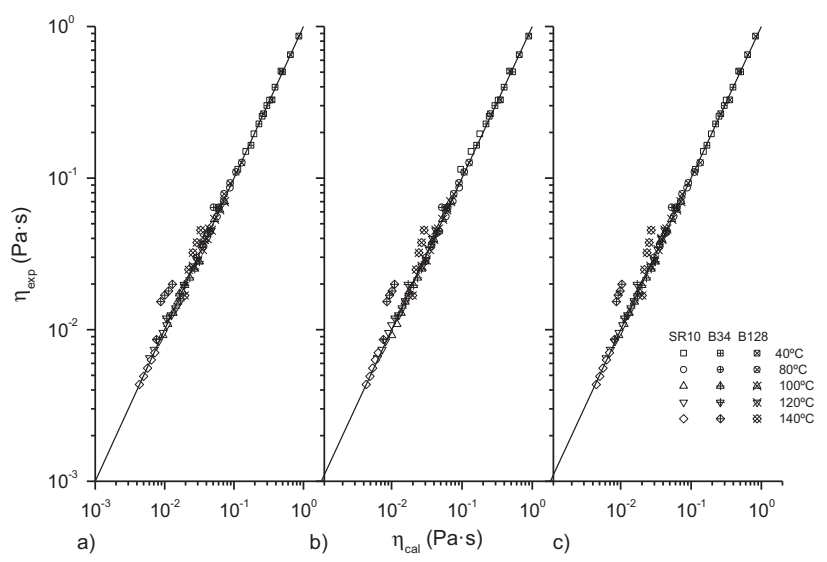

Figure 8

Comparison of experimental and estimated viscosities by using a) FMT's model; b) Yasutomi's model and c) WLF-Barus' model.

depending on the sample. Thus, both FMT's and WLFBarus' models show similar deviations and lower \%AARD values for the SR10 oil ( 2.3\%, Tab. 2-4). B34 drilling fluid shows the highest values of \%AARD and lowest $R^{2}$ correlation coefficient for any model tested, being WLFBarus' model the best fit for this sample. On the contrary, Yasutomi's model shows the lowest values of the \%AARD for the B128 drilling fluid. The use of an empirical exponential function of temperature and pressure to model viscosity data of water-based drilling fluids, oil-based drilling fluids [39] and invert oil mud [40,41] is very common for 
engineering purposes, being the average error higher than those found in this research (around 5\% [42] or even higher [43]).

\section{CONCLUSIONS}

From the experimental results obtained, it can be concluded that model oil-based drilling fluid densities are more susceptible to changes in temperature than to pressure. The Murnaghan equation describes the PVT behavior, in the range of temperature and pressure studied, fairly well.

Different models can predict the evolution of the viscosity of drilling fluids with pressure and temperature. In this sense, free-volume models, based on physical parameters, do fit the viscosity-pressure-temperature data fairly well, showing similar or even lower error than some well-known empirical exponential equations.

\section{ACKNOWLEDGMENTS}

This work is part of a research project sponsored by a FEDER programme (research project CTQ2014-56980-R). The authors gratefully acknowledge the financial support received.

\section{REFERENCES}

1 Khalil M., Mohamed Jan B. (2012) Viscoplastic modeling of a novel lightweight biopolymer drilling fluid for underbalanced drilling, Ind. Eng. Chem. Res. 51, 4056-4068.

2 Zhou D., Zhang Z., Tang J., Wang F., Liao L. (2016) Applied properties of oil-based drilling fluids with montmorillonites modified by cationic and anionic surfactants, Appl. Clay Sci. 121-122, 1-8.

3 Halali M.A., Ghotbi C., Tahmasbi K., Ghazanfari M.H. (2016) The role of carbon nanotubes in improving thermal stability of polymeric fluids: Experimental and modeling, Ind. Eng. Chem. Res. 55, 7514-7534.

4 Hilhorst J., Meester V., Groeneveld E., Dhont J.K., Lekkerkerker H.N. (2014) Structure and rheology of mixed suspensions of montmorillonite and silica nanoparticles, J. Phys. Chem. B 118, 11816-11825.

5 Hussein A.M.O., Amin R.A.M. (2010) Density measurement of vegetable and mineral based oil used in drilling fluids, SPE Nigeria Annual International Conference and Exhibition, 2010, 31 July-7 August 2010, Calabar, Nigeria, SPE 136974, pp. 237-242.

6 Demirdal B., Miska S., Takach N., Cunha J.C. (2007) Drilling fluids rheological and volumetric characterization under downhole conditions, Proceedings of the SPE Latin American and Caribbean Petroleum Engineering Conference, 3, pp. 1616-1623.

7 Kim N.R., Ribeiro P.R., Pessôa-Filho P.A. (2015) PVT behavior of methane and ester-based drilling emulsions, J. Petrol. Sci. Eng. 135, 360-636.
8 Peters E.J., Chenevert M.E., Zhang C. (1990) Model for predicting the density of oil-based muds at high pressures and temperatures, SPE Drill. Complet. 5, 141-148.

9 Hemphill T., Isambourg P. (2005) New model predicts oil, synthetic mud densities, Oil Gas J. 103, 56-58.

10 Demirdal B., Cunha J.C. (2009) Olefin-based syntheticdrilling-fluids volumetric behaviour under downhole conditions, SPE Drill. Complet. 24, 239-248.

11 Hermoso J., Martínez-Boza F.J., Gallegos C. (2017) Organoclay influence on high pressure-high temperature volumetric properties of oil-based drilling fluids, J. Petrol. Sci. Eng. 151, 13-23.

12 Babu D.R. (1993) Effect of P- $\rho$-T behaviour of water muds on static pressures during deep well drilling, J. Petrol. Sci. Eng. 9, 341-439.

13 Zamora M., Roy S., Slater K.S., Troncoso J.C. (2013) Study on the volumetric behavior of base oils, brines, and drilling fluids under extreme temperatures and pressures, SPE Drill. Complet. 28, 278-288.

14 Gandelman R.A., Leal R.A.F., Gonyalves J.T., Aragao A.F.L., Lomba R.F., Martins A.L. (2007) Study on gelation and freezing phenomena of synthetic drilling fluids in ultradeep water environments, SPE/IADC Drilling Conference and Exhibition 2007, 20 February 2007, Amsterdam, Netherlands, Vol. 3, pp. 1013-1020.

15 Zhao S.-Y., Yan J.-N., Shu Y., Zhang H.-X. (2008) Rheological properties of oil-based drilling fluids at high temperature and high pressure, J. Cent. South Univ. Technol. 15, 457-461.

16 Shahbazi K., Metha S.A., Moore R.G., Ursenbanch M.G., Fraassen K.C.V. (2007) Oxidation as a rheology modifier and a potential cause of explosions in oil and synthetic-based drilling fluids, SPE International Symposium on Oilfield Chemistry, Houston, TX, USA, pp. 157-165.

17 Hron J., Málek J., Rajagopal K.R. (2001) Simple flows of fluids with pressure-dependent viscosities, Proc. R. Soc. A 457, 1603-1622.

18 Franta M., Malek J., Rajagopal K.R. (2005) On steady flows of fluids with pressure-and-shear-dependent viscosities, Proc. $R$. Soc. A 461, 651-670.

19 Quiñones-Cisneros S.E., Deiters U.K. (2006) Generalization of the friction theory for viscosity modeling, J. Phys. Chem. B 110, 12820-12834.

20 Tschoegl N.W., Knauss W.G., Emri I. (2002) The effect of temperature and pressure on the mechanical properties of thermo-and/or piezorheologically simple polymeric materials in thermodynamic equilibrium - A critical review, Mech. Time-Dependent Mater. 6, 53-99.

21 Fillers R.W., Tschoegl N.W. (1977) Effect of pressure on the mechanical properties of polymers, Trans. Soc. Rheol. 21, 51-100.

22 Berthe D., Vergne P. (1990) High pressure rheology for high pressure lubrication: A review, J. Rheol. 34, 639-655.

23 Lemmon E.W., Huber M. (2004) Thermodynamic properties of n-dodecane, Energy Fuels 18, 960-967.

24 Wagner W., Pruß A. (2002) The IAPWS formulation 1995 for the thermodynamic properties of ordinary water substance for general and scientific use, J. Phys. Chem. Ref. Data 31, 387-535.

25 Dávila M.J., Alcalde R., Atilhan M., Aparicio S. (2012) P $\rho$ T measurements and derived properties of liquid 1-alkanols, J. Chem. Thermodyn. 47, 241-259. 
26 Hermoso J., Jofore B.D., Martínez-Boza F.J., Gallegos C. (2012) High pressure mixing rheology of drilling fluids, Ind. Eng. Chem. Res. 51, 14399-14407.

27 Hermoso J., Martínez-Boza F.J., Gallegos C. (2014) Combined effect of pressure and temperature on the viscous behaviour of all-oil drilling fluids, Oil Gas Sci. Technol - Rev. IFP 69, 1283-1296.

28 Martín-Alfonso M.J., Martínez-Boza F.J., Partal P., Gallegos C. (2006) Influence of pressure and temperature on the flow behaviour of heavy fuel oils, Rheol. Acta 45, 357-365.

29 Poling B.E., Prausnitz J.M., O'Connell J.P. (2001) The properties of gases and liquids, 5th edn., McGraw-Hill, New York.

30 Moonan W.H., Tschoegl N.W. (1983) Effect of pressure on the mechanical properties of polymers. 2. Expansivity and compressibility measurements, Macromolecules 16, 55-59.

31 Bair S., Mary C., Bouscharain N., Vergne P. (2013) An improved Yasutomi correlation for viscosity at high pressure, Proc. Inst. Mech. Eng. Part J 227, 1056-1060.

32 Murnaghan F.D. (1951) Finite deformation of an elastic solid, Wiley, New York.

33 Fakhreddine Y.A., Zoller P. (1990) Equation of state of a polydimethylsiloxane fluid, J. Appl. Polym. Sci. 41, 1087-1093.

34 Martín-Alfonso M.J., Martínez-Boza F.J., Navarro F.J., Fernández M., Gallegos C. (2007) Pressure-temperatureviscosity relationship for heavy petroleum fractions, Fuel $\mathbf{8 6}$, 227-233.

35 Martínez-Boza F.J., Martín-Alfonso M.J., Gallegos C., Fernández M. (2001) High-pressure behavior of intermediate fuel oils, Energy Fuels 25, 5138-5144.

36 Martínez-Boza F., Fernandez-Latorre F., Gallegos C. (2009) High-pressure viscosity of used motor oil/vacuum residue blends, Fuel 88, 1595-1601.
37 Yasutomi S., Bair S., Winer W.O. (1984) An application of a free volume model to lubricant rheology I - Dependence of viscosity on temperature and pressure, J. Tribol. 106, 291-302.

38 Bair S. (2001) High-pressure high-shear stress rheology of polybutene, J. Non-Newtonian Fluid Mech. 97, 53-65.

39 Houwen O.H., Geehan T. (1986) Rheology of oil-base muds, SPE paper 15416 presented at the SPE Annual Technical Conference and Exhibition, 5-8 October, held in New Orleans, LA, USA.

40 Politte M.D. (1985) Invert oil mud rheology as a function of temperature and pressure, SPE paper 13458 presented at the SPE/IADC Drilling Conference, 6-8 March, held in New Orleans, LA, USA.

41 Hermoso J., Martínez-Boza F.J., Gallegos C. (2015) Influence of aqueous phase volume fraction organoclay concentration and pressure on invert-emulsion oil muds rheology, J. Ind. Eng. Chem. 22, 341-349.

42 Demirdal B., Cunha J.C. (2009) Importance of drilling fluids' rheological and volumetric characterization to plan and optimize managed pressure drilling operation, J. Can. Petrol. Technol. 48, 8-14.

43 Santoyo E., García A., Morales J.M., Contreras E., Espinosa-Paredes G. (2001) Effective thermal conductivity of Mexican geothermal cementing systems in the temperature range from $28{ }^{\circ} \mathrm{C}$ to $200{ }^{\circ} \mathrm{C}$, Appl. Thermal Eng. 21, 1799-1812.

Cite this article as: J. Hermoso, F.J. Martínez-Boza and C. Gallegos (2017). Modeling Pressure-Viscosity Behavior of Oil-Based Drilling Fluids, Oil Gas Sci. Technol 72, 18. 